The Canadian Journal of Higher Education

La revue canadienne d'enseignement supérieur

Volume XXXII, No. 2, 2002 pages 103-142

\title{
"Flags and Slots": Special Interest Groups and Selective Admissions
}

\section{KATHERINE E. LANG \& DANIEL W. LANG}

University of Toronto

\section{ABSTRACT}

This paper combines the results of two studies, one from the perspective of institutions and one from the perspective of students, to determine and define the role played by special interest groups in selecting students for admission to college and university. Although there have been allusions to the existence of selection processes that categorize applicants in terms of various special talents and skills, and of racial, ethnic, or geographic origin, relatively little is known about how widespread those processes are and how they actually operate at highly selective colleges and universities. Also, little is known about how special interest group selection is perceived by applicants and their schools. The studies indicate how and why special interest group selection works, and shows that the process is widely used. The studies also indicate that, although applicants are aware of the process, their perception of it does not coincide with either the motives or the expectations of the colleges and universities that deploy it.

\section{RÉSUMÉ}

Cet article, qui regroupe les résultats de deux études, l'une axée sur l'optique des établissements et l'autre sur celle des étudiants, vise à déterminer et à définir le rôle que jouent les groupes d'intérêt spéciaux 
dans le processus de sélection des étudiants ayant fait une demande d'admission au collège et à l'université. Bien qu'il ait été fait allusion à l'existence de processus de sélection classant par catégorie les candidats, selon leurs compétences et talents particuliers, ainsi que leur origine raciale, ethnique et géographique, on détient en fait assez peu de données sur la mesure dans laquelle ces processus sont généralisés et sur la manière dont ils sont appliqués dans les universités et collèges hautement sélectifs. En outre, on sait peu de chose sur la manière dont les candidats et leur école perçoivent la sélection des groupes d'intérêt spéciaux. Les études expliquent la manière dont fonctionne la sélection des groupes d'intérêt spéciaux et les raisons pour lesquelles celle-ci marche bien et montrent que le processus est appliqué à grande échelle. Les études indiquent aussi que, si les candidats sont au courant de l'existence du processus, la façon dont ils le perçoivent ne correspond ni aux motifs ni aux attentes des collèges et universités qui y ont recours.

\section{INTRODUCTION: TWO CASES IN POINT}

\section{Swarthmore College}

In December, 2000, Swarthmore College, one of the United States' most prestigious and elite liberal arts colleges, announced that it would discontinue its football, wrestling, and badminton teams. This was a shock not only to the Swarthmore community, but also to the larger community of highly selective colleges. As an official of a college similar to Swarthmore noted, "If any school should be able to select any kind of class that it wanted [in order to field a football team] it would be Swarthmore." That observation made sense, at least superficially, because Swarthmore was consistently ranked first or second in the U.S. News and World Report's ranking of American liberal arts colleges, had an applicant to place ratio of over 10:1, and had a one billion dollar endowment to support under 1,400 undergraduate students. Indeed, the average combined SAT score of football players at Swarthmore was 1400 .

So, what was the problem? The explanation given by Swarthmore's president was that the college's varsity athletic teams were taking up too many "slots" in each freshman class. From the point of view of the 
college's athletic coaches, a reduction in the number of "slots" would render their teams uncompetitive (Suggs, 2000). Regardless of the point of view, for many within the college and for virtually everyone outside it who was seized by the dramatic discontinuation of the three teams, especially football, this was the first time that the term "slots" and the admissions selection process that it represented had been exposed. Many asked what, exactly, the process was and how it worked. Moreover, since football had been played at Swarthmore for more 120 years and the "slots" process had been in place for fewer than five years, a question that reasonably followed was whether the problem was varsity athletics or the "slots" selection process. Even some members of the college's senior administration and of the college's Athletic Review Committee had difficulty answering these questions.

\section{The College Choice Project}

In 1999 , researchers at the University of Toronto began a project to determine the factors that influence students' choices of college and university. Unlike other studies that typically inquire about college choice after the choice has been made (Acumen, 1998, 1999; Astin, 1993), this study tracked over 100 students in six secondary schools from the time they first considered applying to a college or university to the time that they actually made selections among the offers of admission that they had received. The tracking comprised personal interviews and survey questionnaires. The participating students' "best friends," parents, and guidance counselors were also interviewed and surveyed.

Well over half of the students who participated in the project indicated that they believed that Canadian and, especially, American colleges and universities deployed some sort of special interest or quota methodology in their selection processes for admission, and that their chances for admission would be greater if they were identified with a special interest group. The special interest groups most frequently mentioned were athletics and ethnic or geographic origin. Although the College Choice Project focuses on Canadian students and the special interest group phenomenon is primarily American, nearly $40 \%$ of the participants in the project were 
applying to colleges and universities in the United States in addition to those in Canada.

Virtually none of the students and only one or two guidance counselors demonstrated any understanding of the actual role special interest group membership plays in the admissions process. At the same time, however, virtually all of them were convinced that the practice of selective college admissions existed, in Canada as well as the United States, and that it made a significant difference in admissions.

\section{The Questions}

So, from an institutional point of view (the Swarthmore College case) and from a student point of view (the College Choice Project) it appears that the role, prevalence, and meaning of the "special interest group" in selective college admissions are neither well known nor carefully defined. Several questions follow from these cases. One is what motivates colleges and universities to deploy a selection process that includes special interest groups. Another is how the process actually works. And another is what difference does it make, for example in terms of affecting an institution's ranking in league tables. A third is how widespread is the practice?

\section{SCOPE}

\section{The Institutional Perspective}

The purpose of this part of the study is to examine the relationship between admission selection processes, as they relate to special interest groups, affirmative action initiatives and other quotas, and overall college rankings for NCAA Division III schools in the United States. Student athletes, as a special interest group, are used to illustrate the issue and make comparisons because athletes are to a large degree typical of all groups that are admitted on some sort of quota basis. That could not be said about other special interest groups. In most cases, athletes constitute the largest special interest group.

An "affirmative action" program, in this context, refers to any admissions initiative that favours an applicant based on some defined 
personal characteristic such as race, athletic ability, geographic origin, program of study, family history, or other non-scholastic talent and attribute. In examining this connection, the study addresses the treatment (equitable or otherwise) of athletes in the selection process as compared to other special interest groups, the degree to which separate affirmative action programs work together to meet pre-determined admissions quotas, and the effect that special interest selection programs have on rankings.

The study focuses on NCAA Division III institutions for three important reasons. First, those colleges and universities generally attract a wide variety of highly qualified students. Second, they are selective in admissions. Third, they support a proportionately large number of sports teams at all levels, as well as numerous other activities that might be regarded as "special interests" for the purposes of admission.

Additionally, and methodologically important, NCAA legislation prohibits special financial treatment for student athletes in Division III institutions. In this way, student athletes at NCAA Division III colleges and universities are like other all other students in that other special interest groups do not normally receive special financial treatment. The institutions and the special interest groups in them are thus made comparable. Moreover, this NCAA rule eliminates institutional wealth and personal wealth as factors in the recruitment and selection of students to whom a special interest label is attached during the selection process.

\section{The Student Perspective}

The study from the student perspective asks different but related questions. Are students aware of special interest group selection? Do they believe that it will affect their chances for admission? Do students perceive a connection between institutional quality and prestige, and the diversity that special interest group admission is supposed to produce? Do students rank prestige ahead of quality, and if so, do they associate name recognition with athletic success? Do students "game" the application process to associate themselves with what they believe to be a special interest group designation? 
These questions, and others like them, were asked mainly in the interview component of the College Choice Project. Each participant in the project could generate as many as six interviews: three with the student, one with the student's "best friend," one with the student's parent(s), and one with the student's guidance counselor. Because the survey component of the project occurred near or at the end of the "choice" process, some questions were added to reflect the interest in special interest group admission which was demonstrated in the interviews.

It is important to explain that, in terms of understanding college choice, special interest group selection was not a deliberately or especially identified factor. Instead, it was one factor among many. Nor was there an attempt made to ensure that, among the participating students, there would be a significant number who would be applying to colleges and universities in the Unites States which deployed special interest groups in their selection processes. The extent of interest in American colleges and universities, and in special interest group admission became evident only after the project was underway.

\section{METHOD}

\section{The Institutional Perspective}

Data were collected by soliciting the views of deans of admissions at approximately 50 selective NCAA Division III colleges and universities using a survey. A dozen Canadian universities also received the survey. The survey was distributed via email. Responses were submitted to a www-site, with the provision that if a respondent preferred an alternate form of communication, this would be accommodated. In the end, a few surveys were completed by telephone or by post.

In addition to the information that was sought through the survey, basic but important information was collected from college and university calendars (for example, about the number of athletic teams that were supported by each institution), from U.S. News and World Report annual surveys and rankings (for example about the degree of selectivity of each institution), and from admissions application forms and instructions (for example, to learn whether or not admissions processes were transparent 
enough for students to know whether or not special interest group selection processes were in place). The assembly of this information would make it possible to later align certain institutional responses with, for example, levels of selectivity.

\section{The Student Perspective}

Six secondary schools participated in the College Choice Project:

- St. Clement's School, an all-female independent school in Toronto, Ontario.

- St.Michael's Choir School, an all-male independent Catholic school in Toronto.

- University of Toronto Schools, a co-educational semi-public school for gifted students in Toronto. Admission to UTS is based solely on academic merit.

- Martingrove Collegiate Institute, in Etobicoke, the western suburb of Toronto, a co-educational public school that predominantly prepares students for university. Martingrove has a large ethnic population.

- Saint Mary Roman Catholic Secondary School, a co-educational, publicly-funded Catholic school in Pickering, Ontario, a semi-rural suburb east of Toronto.

- O'Neil Collegiate and Vocational Institute, a comprehensive co-educational public school on Oshawa, Ontario, an industrial city about 60 kilometers east of Toronto. Oshawa has one of the lowest rates of postsecondary participation in the province.

These schools were selected for several reasons. First, they represent a broad array of secondary schools: single gender, co-educational, independent, public, comprehensive, elite, secular, and sectarian. Second, each takes a somewhat different approach to guidance counseling for college placement. This was a potentially important criterion because many studies of the factors that influence college choice indicate a major role played by guidance counselors (Fisher, 2000).

The schools also represent varied student populations in socioeconomic terms. The first step prior to the final selection of schools was 
to gather the postal codes of all students who were in their final years of study. The postal codes were then matched to Census data from Statistics Canada. Specifically, the postal codes were matched to data about household income, employment of parents, and educational level of parents.

The postal code-to-census data match was also used to later identify the socio-economic background of individual students. It was used as well to validate self-reported information about family income and parental education which was collected by questionnaires that were given to students before their first interviews.

The selection of schools, or, more exactly, types of schools, corresponds to the schools that were part of a similar study that was conducted in Los Angeles, California, between 1995 and 1996 (McDonogh, 1997). This was done to allow for comparisons of Canadian and American findings.

After the schools were selected, the guidance counselors in each were asked to identify students who in their judgement were "typical" of students who would be applying to university in the coming year. The point of reference for "typical" was each school individually. "Typical" meant students who were neither exceptionally strong nor exceptionally weak as prospective applicants. All of the students thus identified received a package that contained information about the project, a preliminary questionnaire, and a consent form. The goal was to have about ten participants from each school; approximately the rate of participation in the Los Angeles study. The rate of voluntary participation was higher than expected. To avoid the introduction of an artificial selection factor, all students who volunteered were invited to participate. As a result, the number of students in the Canadian study is more than twice as large as the number in the American study.

During the first interview each student was asked to nominate a "best friend" who would then be invited to participate in the study. This was done to learn about the role played by peers in college choice. The "best friends" who agreed to participate also were interviewed and sent a survey questionnaire. Also after the first interview, questionnaires were sent to parents to ascertain their role in their children's college choice. Some parents also volunteered to be interviewed. 
Depending of information collected in the first interview, follow-up interviews were conducted either in April, for applicants who had applied for Early Admission or Early Action, or in June (by which time virtually all applicants had received decisions about their applications). At that time, all participants, including "best friends" and guidance counselors, received Likert scale survey questionnaires that inquired about 24 factors that influence college choice. In the case of counselors, they were asked to score the questionnaires twice: once in terms of how they thought students would make their selections and once in terms of how they thought students should make their selections.

Finally, grades for each participating student were collected. These were the grades that were submitted to the colleges and universities to which each respective student applied. In most cases, the grades were not final grades. One reason for collecting this information was to verify the reliability of self-reported information about the students' academic strength that was collected in the first interviews. The ultimate point was to learn whether or not students' perceptions of their own academic strengths led to self-selection in their choices of college.

\section{BACKGROUND}

\section{Special interest as exclusion}

The history of higher education during the 18th and 19th centuries, in both Canada and the United States, is characterized by sectarian factionalism. This was reflected in admissions policies that gave priority in selection to persons of particular religious denominations. The reverse was also true; in some cases admissions policies were used to exclude persons of some denominations (into the 20th century). On the one hand, the Swarthmore College community, which still has strong connections to the college's Quaker roots, should not have been surprised, on the reasoning that special interest groups or their equivalent have been around for a long time. "Slots" was perhaps, therefore, just a new term for an older idea. But, on the other hand, it was a surprise, which suggests either that the new terminology was not associated with the old practice 
or, more likely, that the old (and new) practice was never fully acknowledged and understood.

Since the 18th century, North American colleges and universities have implemented admission policies that reflected the changing values of society as well as changes in the roles that the institutions were expected to play. At the turn of the 19th century only the sons of wealthy, status-bearing members of society were invited to attend the relatively small number of prestigious colleges and universities that had established themselves as pillars of academic reputation in the United States. These institutions were seen as places where the social or religious elites could send their sons and, in a very few cases their daughters, to ensure a smooth transition from childhood to adulthood, to afford them the highest level of social prestige, and to provide them with access to certain professions, predominantly the church.

Some of this pattern was broken down by the inception of the American Land Grant colleges in the latter third of the century, but the pattern remained largely in place. From an admissions point of view, the pattern was as much exclusionary as inclusionary. From this observation, however, it does not necessarily follow that selection processes based on the deployment of special groups, however labeled, was a widespread practice. Throughout the 19th century and into the 20th century supply often exceeded demand. Colleges and universities, even those of high repute, were not so competitive that elaborate selection processes were necessary (Geiger, 2000). To the extent that there were enrolment targets or quotas, they operated more in the direction of negative action than of affirmative action. The limited access that Jews had to American and Canadian colleges and universities is an example of a "special interest group" that was created to limit, rather than expand, participation of certain groups of students. The closest that one came to speaking openly about athletes as a special interest group was Charles Eliot's reference as president of Harvard to "bodily excellence" (Eliot, 1908). Though this reference might seem so out-of-date as to be irrelevant, but it is not. Rather, it is illustrative of how infrequent and how euphemistic discussions of special interest group selection for admission have been. Many years would pass before colleges and universities would again speak as Eliot did. 


\section{Special interest as inclusion}

Broad shifts in the admissions philosophies of America's and Canada's colleges and universities took take place several times during the next century. Most notable were the shifts that occurred immediately following World War II and again in the late 1960s and early 1970s as an era of mass higher education began, and as governments, usually under pressure and sometimes under court order, began to expand civil rights, among which was the right of access to higher education. At this time, the objective of selection for admission fundamentally shifted from exclusion to inclusion. Moreover, because of the terms of some of the orders that emanated from various U.S. federal courts, de facto quotas were set, which in turn made some form of the special interest group a practical necessity in admissions selection processes. The practice became more pronounced as public policies of nondiscrimination gave way to requirements that colleges and universities as well as companies that contracted with the federal government make deliberate "affirmative" efforts to identify and consider minority applicants (Bowen \& Bok, 1998).

From this brief overview we can conclude that the motivation to identify what today are called "special interest groups" has a long and deep origin in North American higher education. We can also conclude that that motivation initially was oriented to exclusion and the denial of civil rights, and for those reasons was seldom openly discussed or even admitted, but is now much more a matter of inclusion and the assurance of civil rights. The shift to inclusion implicitly favoured a more formal and systematic selection process based on the identification and categorization of special interests groups.

\section{The well-rounded student or the well-rounded class?}

During approximately the same period in which political and social forces led to changes in how students were selected for admission a second philosophical transition occurred. From the beginning of the 20th century to the early $1960 \mathrm{~s}$, the focus of admission selection was to enroll "well-rounded students;" those who possessed a broad range of skills that would compliment a college or university's academic programs, 
extracurricular activities, and social atmosphere. This was often referred to as "college as social mixture" (Eliot, 1908).

There was a pragmatic dimension as well. The "well-rounded" approach also solved diseconomy of scale problems at relatively small selective colleges by meeting multiple "special interests" on campus. Students were selected not because they were specialists in any one area, but because they had a strong combination of attributes that made them attractive to the institution in several areas. In athletics this was the era of the "three letter man" - the student who played a varsity sport in fall, winter, and spring.

By the early 1970 s, this admission philosophy began to be altered in major ways. At some institutions, doubts about the desirability of the well rounded student were expressed by faculty members who were concerned that a spectacular mathematician or artist would be passed up in favour of someone with a broader skill set (Shulman \& Bowen, 2001a). As inter-collegiate athletic competition intensified, the search for highly specialized student athletes also became more intense. As a director of admissions said, "It's the same for everybody in the conference. If one school can field a 'nickel package' we all have to." (quoted in Shulman \& Bowen, 2001a) What is especially notable about this is that the college which this director of admissions served was not an NCAA Division I university. It was Amherst, one of the most prestigious and selective colleges in the United States. So a new admission mantra was coined: the search was on to enroll the "well rounded class" (Hoy, 1967; Sack, 2001) instead of the "well rounded student." The idea behind this new strategy was that the super-mathematician should definitely be admitted, along with the outstanding artist, the science whiz, and even the star running back so that the resulting class, taken together, included such an array of talented individuals that it would create an attractively diverse community of learners (Shulman \& Bowen, 2001a). In Canada, the president of the University of Toronto wrote openly and approvingly of the virtue of being "lop-sided" (Bissell, 1968). The same philosophy found its way onto the athletic field where coaches, who previously built strong teams by instructing well rounded "walk-ons," began to build teams by recruiting specialists at each position, and discouraging 
students from playing more than one sport (Menand, 2001). This, in turn, changed the working relationship between athletic departments and admissions offices as coaches became, at least indirectly, participants in the selection process (Shulman \& Bowman, 2001b).

The after-effect of this new philosophy, however, was that very careful attention had to be paid to the composition of each class to ensure that students, as a group, would be sufficiently diverse. The transition from well-rounded student to well-rounded class meant that colleges and universities had to choose more carefully and, especially, more systematically the students they admitted in order to ensure that overall the class exhibited the same broad skill set that had previously been sought in each and every student. It was no longer a given that the incoming class would provide as many athletes, engineers and musicians as was needed to sustain that college's programs and so, the hunt was on to recruit, and ultimately admit, the best and brightest and most specialized students to fill the places in their freshman class - all of this in addition to attending to the racial and ethnic composition of the class.

The implications were somewhat different for colleges than universities. Because universities typically are comprehensive and organized around faculties they could achieve a significant degree of "wellroundedness" simply by reflection of their comprehensiveness. For example, exceptional musicians could enrol in the faculty of music; athletes could enrol in faculties of physical education; artists and dancers could enrol in faculties of fine art, and so on. More significantly, they could do this without being selected on the basis of "special interest" because the university's array of programs was itself an expression of what otherwise would be called special interest. This is one area in which Canadian universities differ from their American counterparts; most Canadian universities are comprehensive while many of the most selective American colleges and universities are predominantly liberal arts at the undergraduate level. This probably explains why no Canadian university that was surveyed reported using any sort of non-academic special interest group selection process for admission from secondary school. Some did report, however, using a sort of "flags and slots" process for managing enrolment among academic programs and among groups of students who were 
differentiated in terms of the revenue that they generated (for example, domestic students and international students).

\section{Special interest as a marketing numbers game}

Additionally, this new focus on special interests in recruitment brought to the surface an external force that has played an increasing role in defining the way that colleges and universities were managed. Although competition among rival colleges and universities is not a foreign concept, the challenge to admit the best students has grown to represent a race of sorts with each school expending great effort to present itself in the best possible light and to offer the most attractive incentive packages to those students whom they covet most. Bowen and Shulman (2001a) note that because sports are so results-driven and quantifiable, athletics provide an outstanding example of this phenomenon, but other examples of intercollegiate competition can be found almost anywhere, "The College Bowl," for example, was for several years a prime-time television program.

Possibly the most influential competition of all is the fight for rankings. As more and more mainstream publications, such as U.S. News and World Report, publish the results of annual surveys ranking the best colleges and universities, the influence these have, or are presumed to have, on the educational marketplace is powerful, and sometimes engenders special interest group behaviour. The most notable of which is early admission.

James Fallows (2001), in a recent analysis of the emphasis placed on early admission, gives the example of the University of Pennsylvania, which was, it appeared, losing its reputation and ability to attract students because of its low placement on various league tables. Through a variety of measures, for example: spending more on buildings and increasing faculty compensation, Penn pulled itself up to sixth place in the U.S. News \& World Report survey (Fallows, 2001). But what really happened? One way that a college or university can make itself look more competitive for the purposes of national rankings is to admit more students under early admission. This is a relatively simple matter of arithmetic. For every place in the freshman class that is filled by early 
admission the ratio of applicant to place is $1: 1$ and the yield rate is $100 \%$. If, for example, half the class is filled that way, the number of places to be filled through regular admission goes down by $50 \%$ thus driving up the remaining applicant per place ratio and increasing the overall yield rate as the $100 \%$ rate for early admission is blended with the lower rate, sometimes as low as $40 \%$ even for elite institutions (Geiger, 2000), for regular admission. It can be reasonably argued that early admission is the single largest special interest group. Setting league rankings aside, some colleges and universities favour early admission applicants because they are "first choice" applicants who will be a good match with the ethos of the respective institution.

In Canada, where early admission is less common (but where declaration of choice often is part of the application process), there are league rankings as well through Maclean's annual ranking. Here the numbers game works differently but still has an element of special interest group arithmetic. To the extent that grades of entering students represent quality, the editors of Maclean's collect data on the grades that students earn the final level courses on which their admission is based. The catch is that Maclean's survey is national, but what constitutes final level courses and grades varies from province to province, so the calculation for the purposes of ranking is essentially based on the pool of applicants from each university's home province, and within that pool on only those applicants who apply directly from secondary school. The Annual Survey also takes the proportions of out-of-province and international students as indicators of quality. These two indicators, whether or not they reliably represent academic quality, engender a special interest group approach to admissions: in-province applicants are separated from out-of-province applicants, who are in turn separated from international applicants.

\section{Title IX}

Title IX of the Educational Amendments of 1972 is the landmark U.S. legislation that bans sex discrimination in colleges and universities whether it is in academics or athletics. Title IX has had a major effect on the deployment of special interest groups in admissions. Title IX states: "No person in the U.S. shall, on the basis of sex be excluded from 
participation in, or denied the benefits of, or be subjected to discrimination under any educational program or activity receiving financial aid" (Title IX, Education Amendments, 1972). Title IX is enforced through the denial of funding. In any college or university that receives any form of federal financial assistance, all education programs and activities, including athletics programs, are subject to Title IX, with which the failure to comply can lead to the denial of federal funding, regardless of its purpose. The Title IX stick is big.

Title IX legislation governs the overall equity of treatment and opportunity in athletics while giving institutions the flexibility to choose sports based on student body interest, geographic influence, budget restraints, and gender ratio. Every one of those criteria could be regarded as a special interest group and are.

With regard to intercollegiate athletics, there are three primary areas that determine whether or not an institution is in compliance with the Title IX legislation. First, financial assistance must be awarded proportionately, based on the ratio of male to female athletes. Second, the selection of sports and the level of competition must effectively accommodate students' interests and abilities. Third, all other benefits, opportunities, and treatments afforded to participants in intercollegiate sport must be equivalent, but not necessarily identical. These criteria operate sport-by-sport as well as institution-wide. Under Title IX, the number of women in intercollegiate sports increased $81 \%$ since its inception (Miller, Heinrich \& Baker, 1998; United States General Accounting Office, 2001). One reason that it is effective is that it is formal and measurable, which in turn makes it a powerful force that pushes colleges and universities in the direction of special interest group admission. The term "slots" that Swarthmore used in explaining its decision to discontinue three of its varsity athletic teams is very much within the idiom of Title IX (Thelin, 2000). 


\section{SURVEY RESULTS}

\section{Previous studies}

Before reporting and discussing the results of the two studies that are combined a word should be said about the absence of previous results. Why is it that the deployment of special interest groups in selective admissions is, either in reality or perception, mysterious? One answer has already been given; until the 1960s the purposes that special interest group selection processes typically served were largely unspeakable. Colleges and universities did not want to admit that, for example, they were discriminating against Jews. Another answer has been alluded to: although colleges and universities openly sought to construct classes of a certain "social mixture" most used euphemisms like "bodily excellence" to describe what that mixture comprised.

Although not really taboo, like racial or ethnic discrimination, the economics of Title IX as it affects college and university costs are complex and inaccessible. Nevertheless, it is clear that affordability is a factor that leads to a special interest group approach to admission.

There has been some discussion of the special interest group phenomenon. In 1966, in a report prepared for the College Entrance Examination Board, B. Alden Thresher, spoke about the "great sorting" in college admissions and referred expressly to "coordination with the athletic department" (Thresher, 1966). Although not necessarily critical of the deployment of special interest groups in admissions, Thresher observed that it was characteristic of a "collegio-centric" way of thinking about admissions which sometimes masked unintended abuses. He also pointed out that, even if special interest group admission was entirely desirable, it could still go wrong if its taxonomy inaccurately lumped incomparable applicants together.

Although Thresher sought to explain why the "sorting" was going on, and why it was sometimes useful and sometimes not, he failed to explain what was going on. The first description of the role of special interest groups in selection for admission appeared in Choosing a College by John C. Hoy (1967), who at the time the book was written was Dean of Admissions at Wesleyan University. Hoy made two things 
clear: that colleges and universities like Wesleyan, which is very highly selective, were committed to the "well rounded class" approach in selecting students for admission, and that "special interests and talents" were the key to success in that approach (Hoy, 1967). A few years later under a different dean of admissions, Wesleyan went further and prepared a manual that named the several special interest groups, which Wesleyan called "debate groups," and explained how an application moved among the groups until a decision was reached about it (Wesleyan University, 1973). The groups were science, music, performing arts, languages, minority status, athletics, international geographic origin, local geographic origin, and children of alumni. The Wesleyan manual also revealed that for some groups (the ones named were music, theatre, and athletics) applications were reviewed and appraised by persons outside the admissions committee. Finally, the manual explained, in a combination of pragmatism and philosophy, the basic idea behind special interest groups in its admissions process:

We know that the opportunities available at Wesleyan are many and varied, but we also know that Wesleyan's capabilities and capacities are not unlimited or universal. Consequently, the selection process must identify and favor those interests, aspirations, and potentials which Wesleyan can serve best. (Wesleyan University, 1973).

In 1985, Robert Klitgaard, who was Special Assistant to the President of Harvard University and chair of one its admissions committees, described the direction in which he thought that the selection process at Harvard might evolve. In that description he named several special interest groups: athletes, performing artists, students interested in under-subscribed departments, and alumni and faculty children (Klitgaard, 1985).

The most recent study to acknowledge and discuss the role of special interest group admission, $A$ is for Admission, which uses Dartmouth College as an example, is remarkably like the Wesleyan manual. It is different mainly in terms of terminology: instead of referring to "debate groups" or "special interest groups" it refers to "flags" that are used to identify applicants with special talents, just as Swarthmore used the term 
"slots" (Hernandez, 1997). Unlike the Wesleyan manual, however, which was actually prepared by the college, the Hernandez study did not have the endorsement of the college. Dartmouth disavowed it without saying that it was inaccurate.

Once there were some studies that revealed the existence of special interests groups, there were a few collateral investigations of the predictive value of the student characteristics that special interest group admissions typically recognized. The results are mixed. There is some evidence that students who exhibit the attributes on which special interest group admissions usually place a premium are more motivated and have higher aspirations than other applicants, but this does not necessarily mean that they perform better or are more persistent in college or university (Hearn, 1984; Hossler, 1999; Hossler \& Stage, 1992; Hossler, Schmit \& Vesper, 1999 Shulman \& Bowen, 2001a).

\section{Current studies: Survey of Institutions}

The statistical data compiled through this research provide a comprehensive look at the use of special interest groups in NCAA Division III colleges and universities. For analytical purposes, the findings of this study have been grouped according to the question assembly used in the survey instrument. In this way, though it might appear that some questions have been skipped, related data have been grouped to provide a complete analysis of particular issues.

In your admissions process, are any applicants assigned special interest status for review and consideration? The overwhelming majority of the schools that responded indicated that they assign special interest status to locate applicants in one or more groups. The groups to which special interest status applied varied depending on the institution. In agreement with Shulman and Bowen's (2001a) research findings, $86 \%$ of respondents indicated that athletes were given special consideration in their admissions process, while $57 \%$ gave special consideration to "legacy" applicants (those applicants who are close relatives of alumni). Of the responding institutions, $43 \%$ reported that applicants with exceptional talents in the performing arts warranted special consideration and $57 \%$ reported that students from diverse geographic locations are given 
special status as well. Of the respondents, $14 \%$ gave special consideration to those applicants with fundraising and development potential for the school, and two-thirds percent gave special consideration to applicants from socioeconomically disadvantaged backgrounds. Program of study is given special consideration by approximately $29 \%$ of participants, and $43 \%$ gave special status to international students. One respondent also indicated that there were "other" student groups that received special status in the admission process. Lastly, ethnic and racial minority groups were "flagged" for special consideration by all of the schools that reported. Given the consistent emphasis placed on civil rights, and racial and ethnic diversity during the past fifty years, this result is not surprising and accords completely with Bowen and Bok's findings (1998).

Although this survey was conducted 25 years after the first acknowledgement and identification of specific special interest groups (Wesleyan University, 1973) the list of special interest groups reported by the institutions that responded to the survey was virtually the same as the list reported by Wesleyan. The list also accords with Hernandez' description of the selection process at Dartmouth. (Hernandez, 1997).

Can an applicant be assigned to more than one special interest group? A particularly significant finding identified by this research is that all responding schools agreed that applicants could be assigned to multiple special interest groups during the admissions process, and that placement in these groups could occur simultaneously as opposed to consecutively. Although it might seem surprising that there would be $100 \%$ agreement on any policy matters pertaining to a market as broad as the one that exists in American higher education, having special interest applicants considered in this fashion seems to be a common-sensical approach. Depending on the groups afforded special admission status by a particular school, it is foreseeable that an applicant would fall into more than one special interest group. An example of this could be an African-American applicant who possesses exceptional artistic ability. Allowing applicants to be considered simultaneously as members of multiple special interest groups is also economically prudent as it would save time during the decision making process by minimizing the time spent reviewing each file. Additionally, it would be a great disadvantage 
to both the applicant and the institution to issue a decision before all of the applicant's desirable qualities had been fully explored. By allowing simultaneous placement in multiple special interest groups to stand, admissions officers can get a more accurate picture of what the applicant has to offer, and ensuring the admission of those applicants that will bring the greatest benefit to the school. It also favours the applicant by ensuring that his or her best case is considered.

These responses are consistent with Hernandez' report but not with the practice described by Wesleyan, where applicants moved from special interest group to special interest group serially and were never in more than one group at any given time.

How are students identified as being eligible for special interest status? While all responding colleges and universities agreed that the most typical way for a student to be identified for special interest status was by being "flagged" as such by a member of their admissions staff, the number and type of additional identification methods varied greatly. The second most common mode of identification, supported by $86 \%$ of respondents, was self-identification, followed by identification by a guidance counselor at $43 \%$. Approximately $29 \%$ of respondents cited a teachers' recommendation as a method of special interest identification, while the use of separate interest identification forms and identification via organizations that represents special interest students, usually athletes, were each reported by $14 \%$ of participants. In addition, $57 \%$ of respondents suggested "other" ways in which applicants could be recognized as qualifying for special interest status. It is interesting to note that none of the schools surveyed suggested that special interest status could be achieved based on the basis of identification by a professional college counselor or other private consultant not associated with the student's school. The survey did not inquire about the causes of this, but some experts have suggested that it is due to the lack of credibility of some professionals in this field (Hoy, 1967).

The relatively high rates of reported for self-identification and identification by guidance counselors and teachers indicates that, although students and secondary schools might not understand how the special interest group process works, they know it is potentially important. As 
we shall soon see, this aligns with some of the results from the College Choice Project.

Is the same review process used for considering applicants in all special interest groups? All but one admissions office that responded to the survey indicated that the same review process was used to evaluate applicants in all recognized special interest groups. This finding is basically consistent with Hernandez's account of admissions procedures at Dartmouth College (Hernandez, 1997). Bowen and his co-investigators found that while the processes for evaluating applicants were standardized for most special interest groups the priority given to different special interest groups by the admissions process varied (Bowen \& Bok, 1998). Although there are individualized processes in use at many colleges and universities and admission decision are rarely cut-and-dry, the participants in this survey maintain that the key to successful admissions policies is consistency in the evaluation of individual students, and the special interest groups to which they may belong.

Given that most respondents agreed that the review processes used to evaluate all special status applicants should be the same, it is useful to determine whether or not the same people are also involved in the decision making process. An interesting finding was that of those institutions that indicated the use of identical review processes, exactly one-half indicated that the same people participated in the evaluation of special interest applicants in a given group while the other half said that the same group was not involved in the evaluation of all applicants in a specific special interest group. By stating that the same people participate in the evaluation of applicants for a specific special interest group respondents meant that, for example, the head of a music department would be involved in the decision making process for all applicants who had been identified as members of the music or performing arts special interest group, and coaches (and not the head of the music department) would help to evaluate applicants with recognized athletic ability. The flip side of this approach arises when a fixed admission committee is selected to evaluate all applicant files. Typically when this approach is used, faculty and staff members are selected to represent the various recognized special interest groups during the decision-making process, 
but the committee remains unchanged regardless of whether a musician or an athlete is being considered.

Which of the following procedures most accurately reflects the decision making process used by your office?

Model A - All applicants are reviewed and provisional admit and reject decisions are made for some. Only applicants who are neither admitted nor rejected at that stage are assigned for review and consideration as members of special interest groups.

Model B - All applications are reviewed to determine whether or not they meet minimum standards for admission. Only those who meet the standards are assigned to special interest groups for further review and consideration. All other applications are provisional rejects.

Model C - All applications are reviewed to determine which special interest group they should be assigned, but no other provisional decisions are made until the applications have been reviewed at the special interest group level.

Although all admissions offices strive towards more or less the same goal - enrolling the best possible incoming class - the procedures followed to achieve this end vary from institution to institution. Three main admissions models were used in selecting students for admission from special interest groups. Participants in this study were asked to identify which of these models most closely matched the decision making process used by their institutions. This information is useful, not only because it reflects the current trends in the selection process, but also because the policy choices made by given schools tend to illustrate that institution's educational philosophy. For example, the stage at which special interest status comes into play will likely indicate that added weight is given to these qualities when considering applicants for admission.

The first of the three common admissions models, Model A, was reported by $29 \%$ of the offices that responded to the survey. This is the model reported by Hernandez on the basis of her experience in the admissions office at Dartmouth (Hernandez, 1997). Under Model A, the first step in the admissions process is to review all applications and make 
provisional admit or reject decisions for only those applicants who clearly fall into either of those categories, whether or not they have special interest group status. The remaining applications (those that were neither admitted nor rejected during the provisional decision making stage) are then assigned for review and consideration in special interest groups, if such status is warranted. Final decisions are reported to applicants at the same time.

Model B was reported to be in place at $43 \%$ of the responding institutions. In those colleges and universities, the evaluation of applicants began with a determination of whether or not each applicant meets the minimum standards set for admission, and provisionally rejecting all students who do not meet the minimum. No provisional decisions are made about admission. Then only those students who have met the minimum standards are assigned to special interest groups for further review and consideration. In other words, virtually all applicants are admitted from one special interest group or another.

The third model, Model C, which was preferred by $28 \%$ of responding institutions, is somewhat similar to Model B in that all applications are reviewed to determine to which special interest group they should be assigned. However, unlike the previous models, no provisional admit/reject decisions are made at all prior to dividing the applicants into special interest groups. Under this model there are no minimum standards that apply universally to all applicants. This model appears to be most prevalent in less selective institutions and in comprehensive universities with several separate faculties.

Surprisingly, none of the colleges or universities that participated in the survey indicated that their admissions office used an alternative process to evaluate applications. There were no "others." This suggests that the initial question was well defined and clearly phrased, thus indicating reliable results.

Is an identical process used to evaluate early admission applicants and wait list applicants? Many selective colleges and universities today offer both "early decision" and "wait list" admissions options in addition to the regular admission to students who are very keen to attend their institution. The idea behind early decision is that students who are 
certain that they want to attend a given school can apply and receive a decision before the main admission rush begins, provided that they agree to attend the college that offers them early admission. This means that students can "apply early" to only one school and that, if offered admission, they must accept. The thinking that applying early decision will somehow increase an applicant's chance of admission is a commonly held belief among students and some guidance counselors (Fallows, 2001). It is not, however, corroborated by either the Wesleyan manual or the Hernandez report.

In almost every case, the early decision applicant pool is much more homogeneous than those that are formed in the later rounds of the selection process. There are three reasons for this: first, the most outstanding applicants can be reasonably confident that they will be accepted by all of the colleges or universities to which they apply, and therefore do not feel that the need to improve their chances by placing themselves in the early decision special interest group. For them, "wait and see" is a good option. Second, minority group applicants tend not to apply for early decision, usually for financial reasons. Third, many students for whom financial aid is a concern opt not to apply early so they have the opportunity to compare scholarship offers from a variety of colleges. It appears that many athletes take the same point of view, although perhaps with different motives (Shulman \& Bowen, 200lb). The result are early decision special interest groups that tend to be inhabited by affluent and white students (Hernandez, 1997). The Hernandez' findings were more recently confirmed by Fallows (2001). Since the early decision pool is noticeably more homogeneous, and since all colleges aim for overall diversity, it may not behoove a college to accept a significant portion of its students early decision despite the control that this practice gives institutions to optimize yield rates, and in turn boost their rankings in league tables.

The wait list on the other hand consists of those strong applicants who were not offered admission during the regular admissions cycle because there simply were not enough spaces in the class to accommodate all qualified applicants. Students on wait lists are retained and sent offers of admission as the yield rates for the first round of offered admission 
becomes known. Students on wait lists are usually never actually rejected; they are simply notified that the wait lists are closed.

So how then do schools handle admissions decisions for these two groups? According to the respondents to the survey, $86 \%$ of selective colleges and universities evaluate early decision applicants using exactly the same process as they do for applicants in their regular pools. The remaining $14 \%$ indicated that early decision applicants are considered using an alternative method. Although these findings are somewhat contradictory to Hernandez' claims (1997) that schools are significantly more conservative during their early decision evaluation process, they do strongly support the role of consistency as a mainstay in admission policies. Fallows, however, suggested that the competition for admission by early decision is not as stiff as competition for regular admission (Fallows, 2001). That suggestion, significantly, does not imply that different criteria or selection processes apply to early decision admission.

In terms of wait list admission, the findings were identical to those for early decision admission. However, and this is the reason for discussing wait lists at all in this study, being identical also means deployment of special interest groups. For example, if the yield rate for football players or for students of colour is lower than expected, it is to "wait listed" applicants in those groups to which the institution will first turn.

Are targets or quotas set for special interest groups? Perhaps the most interesting and most problematic finding from the survey is that none of the colleges and universities surveyed reported that they used targets or quotas to regulate admission from special interest groups. This is surprising due to the highly quantifiable nature of the admission process, especially in terms of Title IX legislation. The case of Swarthmore College's decision to eliminate three athletic teams provides an example of the uncertainty of this finding. The December 7th, 2000 edition of The Phoenix (Swarthmore's campus news paper) quoted the college's provost as saying " $10 \%$ [of available special interest group "slots"] did not adequately support intercollegiate athletics and the full number of slots (32\%) [that were needed by athletics] was just too big for the college." The article went on to outline the final decision to cut football, wrestling, and badminton as well as the implementation of a 
new admissions target that will limit the number of "slots" for athletics athletes to approximately $15 \%$ of the entering class. While there were probably other issues that played a role in Swarthmore's decision, the rationale offered by the college was predicated almost entirely on the concept of quotas. Shortly after Swarthmore's decision was announced, Amherst College, which coincidentally usually competes with Swarthmore for the number one spot on U.S. News and World Report's annual ranking of American liberal arts colleges, commenced a review of the number of places that its admissions process allocated to varsity athletics. The director of admissions at Amherst, too, talked about slots: "Here we are with only 400 slots and I'm not just looking for a football player or a line-backer with [SAT] scores that are respectable, I'm looking for a left outside linebacker who can blitz." (quoted in Shulman \& Bowen, 2001). So at least some very highly selective American colleges talk in terms of quotas whether or not they admit to using them in their admissions processes.

Are existing representatives of special interest groups (for example, coaches/instructors) given an opportunity to rank by preference the applicants affiliated with their groups during the decision making process? The manual produced by Wesleyan University (1973) acknowledged that for some special interest groups professors and coaches were invited to review applications and advise the admissions committee about applicants' strengths relative to the needs of their programs. Was this an isolated instance or was it then and now a relatively widespread practice?

This process could take many forms but it is most likely a matter of each program's being asked to submit a list of recruited applicants ranked in order to indicate which applicants are most desirable for their purposes and, significantly, without regard to the applicants' other abilities. The most straightforward example of this would likely be a football coach who would submit a list of recruited players whom he feels would contribute to the team. In compiling this list the coach would consider not only the skill of the recruited athletes, but also any skill deficiencies that might exist in the team currently, any vacancies that might result because of graduation, and the likelihood that, based on the coach's 
recruitment efforts, the recruited athlete would accept an offer of admission and if one was received. Obviously, this model could be adapted to fit many recognized campus groups, and it is (Hernandez, 1997; Shulman \& Bowen, 2001b).

Although participants in this study were split evenly when asked whether or not the same persons participated in the evaluation process for students assigned to different special interest groups, they were more supportive of allowing representatives of these groups to submit their input indirectly, for example, ranking by preference. Of the respondents, $71 \%$ indicated that they routinely invited representatives of special interest groups to rank by preference those applicants affiliated with their programs. This suggests that admissions officers recognize the benefits of inviting input from those who have expertise in the applicant's area of talent and specialization, and in the needs of the programs that special interest status is designed to support.

For admissions purposes, how narrowly defined are special interest groups? Logically, it might be expected that larger institutions would have more narrowly defined special interest groups due to a greater student population and a larger number of on-campus activities. However, while this thinking was generally accurate with regard to the colleges and universities in the study with broad and numerous special interest groups, it was somewhat problematic when it came to those schools that reported having more highly specific special interest categories. As would be expected, most small and mid-sized colleges indicated that their special interest groups were either "broad" or "very broad," while the larger universities used more specific definitions to outline their special interest groups. The only notable exception to this was one particular small private college that described its special interest groups as "somewhat specific" meaning that their special interest groups are designed to accommodate relatively narrow student categories (that is there are separate interest groups for each race as opposed to one general category for all students of colour).

How similar are the criteria used to evaluate applicants from special interest groups to the criteria used to evaluate all other applicants? It is a common belief that students who are assigned to special interest 
groups during the admissions process are evaluated using drastically reduced criteria, and are therefore, admitted with inferior credentials (Shulman \& Bowen, 2001b). However, respondents to this survey conclusively reported the use of admission criteria that were either identical (43\%) or very similar $(57 \%)$ to those that are used to evaluate all other applicants. It is worth recalling here that in the case of Swarthmore College's decision to discontinue its football team the average combined SAT score for students on the team was 1400 .

In those situations where slightly different criteria were established to evaluate special interest applicants $75 \%$ of responding institutions indicated that the altered criteria were developed by the admissions office, while the remainder reported that a separate college committee was responsible for establishing these guidelines. In all cases, the admissions office was responsible for applying the relevant criteria to both special interest and non-special interest applicants.

Another noteworthy finding is that at all but one participating institution applicants assigned to special interest groups were required to meet a pre-determined minimum standard for admission at some point during the admission process, and that standard was the same for all applicants.

The institutions polled in this study correspond in terms of male/female ratios and other class composition data with the institutions in the study, which responded to the survey. This indicates that the responding institutions are typical of the larger group of highly selective colleges and universities. Every one of the responding institutions reported that the data they provided for 2000 were representative of their typical entering classes.

What percentage of your 2000-2001 entering class came from special interest groups from, and from which groups? The array of groups identified by the responding institutions was, as noted earlier, very similar for all institutions. The main difference was not in the breadth of special interest groups that were reported. The difference was in the specificity of the groups. For example, about two-thirds of the responding institutions had separate groups for separate sports. These were predominantly but not exclusively larger institutions. When respondents reported about racial or ethnic special interest groups, fewer, 
but still nearly half, reported that separate groups were in place for each minority group; the other half reported a broad "students of colour" interest group. These responses, however, showed no correlation to institutional size. The percentages were reported too infrequently to make conclusions possible. The lowest reported overall rate was $35 \%$; the highest was $67 \%$.

Of prime importance when considering the responses reported to these questions is the determination that the results are, in fact, typical, and therefore could be used to extrapolate findings relative to the broader educational marketplace of highly selective institutions. Describing the participant institutions as "highly selective" indicates that they are competitive with similarly respected institutions, and that they adhere to stringent admission criteria. A good indicator of competitiveness is the application rate, or the ratio of number of applications received per number of spaces in the class. The mean application rate for the schools that responded to this survey was an impressive 4.2 , with a median value of 3.75. Additionally, the mean yield rate at these institutions was .43 , with a median of .42 . These institutions, then, could unquestionably be considered highly competitive.

The selectivity of these schools can also be determined by examining a number of elements in their admissions processes. Firstly, we have seen that highly selective schools tend to support a wide range of special interest groups indicating that they are conscious of the need to carefully select a class that will meet the needs of the institution. Secondly, the data submitted by the participant institutions indicate that, for the most part, a relatively small number of spaces in first-year classes are used up by admitting students from special interest groups. Presumably this is because more selective schools receive applications from a broader and deeper range of qualified applicants, and thus can meet more of their admissions objectives from their regular applicant pool. The selectivity of these institutions is supported by the yield rates reported and the selectivity rankings.

This study was designed and conducted on an assumption that the "flags and slots" approach to the admission of students from special interest groups is characteristic of highly selective colleges and universities. 
The calculation of application rates and yield rates indicates that this assumption was valid. Another means of testing the assumption is to determine where these colleges and universities fit in a major league rankings and surveys.

The most well-known annual college and university ranking system in the United States is easily that which is published each Fall by U.S. News and World Report. Several other major newsmagazines, including Maclean's in Canada, conduct surveys and rankings similar to USN\&WR's. Using the Carnegie Classification of Institutions of Higher Education as the basis for its ranking categories, U.S. News and World Report evaluates for institutions in four general categories: national universities; doctoral, liberal arts colleges - bachelor's; universities - master's; and comprehensive colleges - bachelor's. Information regarding the top undergraduate business and engineering programs is also offered, however, these data are gathered using different criteria.

The institutions examined in this study were all classified in one or two categories: liberal arts colleges - bachelor's or universities - master's. The schools classified by U.S. News and World Report as liberal arts colleges - bachelor's focused almost exclusively on undergraduate education and awarded at least $50 \%$ of their degrees in the liberal arts, while the institutions classified as members of the universities - master's category offered a full range of undergraduate degrees and some master's degree programs but few, if any, doctoral programs. Once this categorical classification had been made, the universities - master's section was further subdivided by geographic area (North, South, Midwest, and West).

According to the rankings of 218 liberal arts colleges - bachelor's and 573 universities - master's schools by U.S. News \& World Report for 2001 , the vast majority of the institutions that participated in this survey were ranked in the top third of their respective categories, with many ranked in the top tenth. These rankings support the aim of this study to examine admission agendas at highly competitive American colleges and universities. This conclusion is strengthened by the fact that the institutions in the study received even higher ranks in U.S. News and World Report's selectivity sub-section, which indicates that not only 
were these schools among the most competitive in the United States, but were also the most selective in terms of admissions standards. These results, coupled with the earlier findings, strongly suggest that not only are "flags and slots" admissions strategies for special interest groups designed to support the educational mission of the institution but also, these strategies play a role in determining how the public views the school in relation to its competitors.

\section{Current Studies: The College Choice Project}

The results of the College Choice Project confirm several important points from the institutional survey.

First, applicants see the real or presumed use of "flags and slots" selection strategies as indicative of a highly selective admissions process, and in turn of high quality and prestige. In the interview and the survey components of the College Choice project two related questions were pursued: How does an applicant know that a college or university is of high quality? Does the applicant perceive a difference between quality and prestige or reputation?

Only $23 \%$ of participating students said that they referred to Maclean's, U.S. News and World Report, or other ranking surveys. An even smaller percentage, $12 \%$, said that their choice of college or university was influenced by rankings insofar as quality was concerned. Every principal and guidance counselor who participated in the project reported that they actively discouraged students from relying on rankings. The project interviewers made a point, when they visited each participating school, to determine whether or not the school's guidance office had a copy of a national ranking survey. Only one did, and that one was Maclean's. Patricia McDonogh's study of college choice in Los Angeles indicated a similar skepticism towards ranking schemes as measures of quality (McDonogh et al., 1998).

Over two-thirds of the students who were interviewed said that they took the difficulty of being admitted to a college or university as a surrogate for the institution's quality. That assumption was even more pronounced (over 90\%) among the students who applied to an American college or university. They indicated further that an admissions selection 
process that sought information that would allow a student to be classified to a special interest group was evidence of an intense competition for admission. One student who was interviewed made the point well: "They [the institutions that deploy 'flags and slots'] have to do that because they have so many applicants with high grades and high SATs that they have to find other ways of picking students." That student was closer to the point than she might have realized. As the level of competition for admission intensifies from what the Carnegie Council called "admissibility" to "selection" the process of selection shifts away from academic competence to personal characteristics and traits that "commend themselves for consideration" and would otherwise be called special interests (Carnegie Council on Policy Studies in Higher Education, 1977).

That quotation, however, also demonstrates that students do not understand how special interest group selection works or, even, what its purpose is. No participating college or university reported that special interest group selection was used to improve the predictive value of the admissions process. Moreover, there is evidence that, even if that were the purpose of special interest group selection, it would not work (Hossler, Schmit, \& Vesper, 1999; Klitgaard, 1985; Shulman \& Bowen, 2001a).

Because of the rising cost of tuition, even at public colleges and universities, and because of reports from guidance counselors that good students sometimes make bad college choices, the College Choice Project in its interview component and in its survey component sought to determine the extent to which applicants drew distinctions between quality and reputation as factors in their choices of college and university. Just over $70 \%$ indicated that, in terms of future job opportunities and of subsequent admission to graduate schools and professional schools, reputation might be more valuable than quality. In the survey component, where quality and reputation might have been regarded as different versions of the same query, a clear difference was perceived as each factor received different scores. Quality ranked higher (just under $90 \%$ of all respondents "strongly agreed") than reputation as just under $80 \%$ "strongly agreed" that it was a factor in their college choice. Compared to other post-admission surveys (Acumen, 1998, 1999; Astin, 1993) the relatively high ranking of reputation is significant. Parents, in that part of 
the College Choice project, ranked reputation higher than quality. This was true of virtually all parents of students who were applying to American colleges and universities. These results are similar to those found in an American study of students in Ivy League colleges and universities who were asked to rank the factors that influenced their college choices. "Prestige and name recognition" ranked first, one tenth of a point ahead of "academic program" (Greene, 1998). In the College Choice Project, this was the area in which the views of guidance counselors most differed from the views of students. Counselors tried to discourage students from selecting colleges and universities on the basis of their reputations instead of the quality and suitability of their programs; the majority of students discounted that advice, a fact that counselors acknowledged in responding to the would or should questionnaire.

Does institutional diversity add to a college or university's reputation? This is a key question that brings the two parts of the study, the institutional perspective and the student perspective, together. At its core the purpose of special interest group selection is diversity; it as about the composition of each incoming class of students. Applicants think that colleges and universities favour diversity in their admissions processes, and they also think that the "flags and slots" approach to admissions is typical of the best and most prestigious institutions. Applicants are right; this study shows that highly selective colleges and universities are very likely to deploy some sort of selection process that is based on special interest groups, and that the relationship correlates directly: the more selective the institution, the more prevalent the deployment of "flags and slots."

But the colleges and universities might not be right about the diversity that "flags and slots" produces. First, "flags and slots" advances diversity as defined by the well-rounded class as opposed to the wellrounded student. In other words, success in being admitted under the special interest group approach often depends on the applicant's being at least somewhat lop-sided, or at least being able to present oneself on those terms. Most students and parents, and many guidance counselors who participated in the College Choice Project believed that to be true of American colleges and universities. No participants believed that Canadian universities took a "flags and slots" approach to admission, but 
a majority of the participants (three-quarters) also thought that admission to Canadian universities should include some dimension of "flags and slots" for things like athletics, leadership, and performing arts, but not a racial, ethnic or geographic dimension. There might be an intuitive logic in that view because as the competition for admission to Canadian universities increases it may seem to some applicants that some factors other than grades ought to enter the selection equation. That, however, is not the same as using other factors to increase diversity as special interest group selection does.

Second, there is little evidence that a "flags and slots" approach to admissions produces diversity that enhances either quality or reputation (Toma \& Cross, 1998). Although most of the institutions that participated in this study said that they did not use separate or different criteria to select applicants from special interest groups, a major study undertaken between 1994 and 2000 demonstrated that varsity athletes who were admitted to selective American colleges and universities presented academic credentials that were below average for their respective institutions (Shulman $\&$ Bowen, 2001a). In 2000, the Arts \& Science Group conducted a survey of students who were then applying to college or university and asked them whether or not an institution's success in athletics affected their choice. Of those students, $73 \%$ said that it did not. Nearly $40 \%$ said that they did not even know whether or not the colleges to which they were applying were in NCAA Division I, II, or III (Suggs, 2001).

\section{"Flags and Slots" and Economy of Scale: A Final Question}

Our investigation will end as it began by using Swarthmore College as an example. If one reflects on the problems with the "flags and slots" approach as it is deployed at Swarthmore as well as by Amherst College and other small, very highly selective colleges an additional question emerges. What difference does institutional size make in the deployment of special interest groups? The answer suggested by this study is that size can make a big difference. As the director of admissions at Amherst said, as the "flags and slots" process has evolved, it is not just a matter of selecting a class with a certain number of athletes, or even a certain number of athletes for a particular team, or even further, a certain number of 
athletes for a particular position on a particular team, it sometimes is a matter of a certain number of athletes who can play a particular position in a particular way. The same could be said about the needs of a college orchestra for students who can play specific instruments, or of a college with too few physics majors.

Although this study and others (Hernandez, 1997; Wesleyan, 1973) indicate that there is a lot of consistency among institutions with regard to the talents, skills and attributes that qualify for special interest group status in the selection process, there is not as much consistency with regard to the level at which they operate. Swarthmore, for example, appears to have taken the "flags and slots" methodology down to a fine level of detail: there was an overall number of "slots" which was then sub-divided to varsity athletics, as well as to other special groups that were of interest to the college, and from there to certain varsity teams. Moreover, and adding a further level of detail, Swarthmore appears to have followed a version of Model C. Most students were admitted from one special interest group or another, and were credited to only one special interest group or team. Coaches of varsity teams appeared to make no allowance for "walk ons" in meeting their "slot" targets. Coaches as a group did not appear to take into account year-to-year fluctuations in the needs of particular teams. To borrow a term from management, Swarthmore's deployment of "flags and slots" was "wound very tightly." The number and assignment of "slots" was fixed, and there was little room for flexibility. In other words, Swarthmore's use of "flags and slots" was more characteristic of a large institution than of a small one.

Large and small are clearly relative terms in this context. Swarthmore, in terms of "flags and slots," is very small with about 1,300 students. Dartmouth, where the undergraduate population is about four times greater than Swarthmore's, is relatively large. Wesleyan is about twice as large as Swarthmore. Yet neither Wesleyan nor Dartmouth appears to have taken the "flags and slots" to level of detail that Swarthmore does. Amherst is slightly larger at about 1,600. Amherst is experiencing problems similar to Swarthmore's, although, in the case of athletics, with a "the Devil made me do it" pragmatism. 
Some large Canadian universities, the University of Toronto for example, are beginning to deploy what might be described as an academic version of "flags and slots." As previously noted, Canadian universities that were surveyed did not report taking a "flags and slots" approach to the selection of special interest groups. Some, however, did report using the approach to manage enrolment among academic streams in large programs like Arts and Science, and among categories of students who are differentiated on the basis of revenue generation: in-province applicants, out-of-province applicants, and international applicants. In these cases the effect of size is different. It is large size that makes "flags and slots" necessary. For example, not everyone can be a pre-med student, nor can some small, highly specialized programs survive unless a selection process in effect steers international students to them.

\section{CONCLUSION}

The line that divides diversity and angularity is indeed very fine. Whatever the reasons, both good and bad, for using special interest groups in selecting students for highly competitive colleges and universities, one cannot assume that the "flags and slots" approach will perform equally regardless of institutional size and regardless of the purpose for which it is deployed. Moreover, the de facto purposes of "flags and slots" as understood by colleges and universities may be understood quite differently by students and schools. Yet the existence of one, we know from this study, can affect the behaviour of the other. Thus the actual result can be different from what either party expected. An interesting and perhaps controversial example of this may be evolving in Canada.

The Canada Millennium Scholarship Foundation is beginning to investigate and promote the idea of merit scholarships (Gucciardi, 2002). Specifically and more to the point, the Foundation is investigating a selection regime for merit scholarships which is very similar to the "flags and slots" approach as it is used by highly selective American colleges and universities. Here are some of the categories that the Foundation is investigating for the purposes of selection: "extra-curricular," "talent," "athletic," "special circumstances," and "regional." This terminology is remarkably 
similar to what the American universities in this survey called "special interest groups." As a matter of practical fact, they would function as special interest groups. And if they did, Canadian students and schools would soon respond to them as students do to the "flags and slots" processes that are already in place in highly selective American colleges and universities. What is different, of course, is that these "flags and slots" would be used to award scholarships. At least, that would be the officially avowed purpose. Yet is difficult to imagine that the selection of students for admission could remain for long different from the selection of students for prestigious merit scholarships. One purpose will lead to another.

\section{References}

Acumen Research Group. (1998, 1999). University Applicant Survey. London, ON: Acumen Research Group.

Astin, A. (1993). What matters in college: Four critical years revisited. San Francisco, CA: Jossey Bass.

Bisell, C. (1968). The strength of the university. Toronto, ON: University of Toronto Press.

Bowen, W., \& Bok D. (1998). The shape of the river: Long term consequences of considering race in college and university admissions. Newark, NJ: Princeton University Press.

Carnegie Council on Policy Studies in Higher Education. (1977). Selective admissions in higher education. Washington, DC: Jossey-Bass.

Eliot, C.W. (1908). University administration. Boston, MA: Houghton Mifflin.

Fallows, J. (2001). The great college hustle. The Atlantic Monthly, September.

Fisher, L. (2000). The role of the guidance department and its counselors in the university advising process. Unpublished Masters Research Project, University of Toronto.

Geiger, R. (2000). Markets and history: Selective admissions and American higher education since 1950. History of Higher Education Annual, 20, 93-108.

Greene, H.R. (1998). The select: Realities of life and learning in America's elite colleges. New York, NY: Harper Collins Publishers. 
Gucciardi, F. (2002). Encouraging, fostering, and rewarding the new citizen: An investigation in merit scholarship models. Paper presented to the Annual Meeting of the Canadian Society for the Study of Higher Education, Toronto, ON, May.

Hearn, J. (1984). The relative roles of academic ascribed and socio-economic characteristics in college admissions. Sociology of Education, 57, 22-30.

Hernandez, M. (1997). A is for admission. New York, NY: Warner.

Hossler, D., Schmit, J., \& Vesper, N. (1999). Going to college: How social, economic, and educational factors influence the decisions students make. Baltimore, MD: The Johns Hopkins University Press.

Hossler, D., \& Stage, F. (1992). Family and high school experience influences on the postsecondary plans of ninth grade students. American Educational Research Journal, 29, 425-451.

Hoy, J.C. (1967). Choosing a college. New York, NY: Dell Publishing.

Klitgaard, R. (1985). Choosing elites: Selecting the "Best and Brightest" at top universities and elsewhere. New York, NY: Basic Books, Inc.

McDonogh, P. (1997). Choosing colleges. Albany, NY: SUNY Press.

McDonogh, P., Antonio, A., Walpole, M., \& Perez, L. (1998). College rankings: Democratized college knowledge for whom? Research in Higher Education, 39(5), 513-533.

Menand, L. (2001). Sporting chances: The cost of college athletics. The New Yorker, January 22, 84-88.

Miller, J.L., Heinrich, M.D., \& Baker, R. (1998). A look at Title $I X$ and women's participation in sport. Paper read at Western Psychological Association, Albuquerque, NM, April.

Morse, R., \& Flanagan, S. (2001). How we rank schools, in America's best colleges 2002. U.S. News and World Report, August.

Sack, A. (2001). Big-time athletics vs. academic values: It's a rout. The Chronicle Review, January 26, B7-B10.

Shulman, J., \& Bowen, W. (2001a). How the playing field is encroaching on the admissions office. The Chronicle Review, January 26, B8-B9.

Shulman, J., \& Bowen, W. (2001b). The game of life: College sports and educational values. Newark, NJ: Princeton University Press.

Suggs, W. (2000). Swarthmore kicks football out of college. The Chronicle of Higher Education, December 15, A55-A56.

Suggs, W. (2001). In choosing colleges, students give little weight to the quality of sports teams, poll finds. The Chronicle of Higher Education, March 14. 
Thelin, J.R. (2000). Good sports?: Historical perspective on the political economy of intercollegiate athletics in the era of Title IX, 1972-1997. The Journal of Higher Education, 7l(4).

Thresher, B.A. (1966). College admissions and the public interest. New York, NY: College Entrance Examination Board.

Toma, J.D., \& Cross, M.E. (1998). Intercollegiate athletics and student college choice: Exploring the impact of championship seasons in undergraduate applications. Research in Higher Education, 39, 633-661.

United States Department of Labour. (2001). Overview of Title IX. http://bailiwick.lib.uiowa.edu/ge/Title_IX.html

United States General Accounting Office. (2001). Intercollegiate athletics: Four year colleges' experiences adding and discounting teams. Washington, DC: United States General Accounting Office, March 8.

Wesleyan University. (1973). The schools committee manual. Middletown, CT: Wesleyan University. 